\title{
The science of science communication
}

\section{Baruch Fischhoff $^{a, 1}$ and Dietram A. Scheufele ${ }^{b}$}

a Department of Social and Decision Sciences, Carnegie Mellon University, Pittsburgh, PA 15213-3890; and ${ }^{\mathrm{b}}$ Department of Life Sciences Communication, University of Wisconsin, Madison, WI 53706-1215

We all need science for making effective decisions in our lives. Are the expected benefits of a medical procedure worth its risks? Does it make sense to rebuild homes along the seashore after a hurricane? How good are the predictions for storm surges? Should we sign a lease for hydrofracking on our property? What are the risks to our drinking water? Science is, potentially, the best source for the evidence needed to answer these questions. Realizing that potential will require effective two-way communication with those whom science hopes to serve-so that it produces relevant information and conveys it in a credible, comprehensible form. This special issue of PNAS presents scientific foundations for that communication.

Its contributions recognize that communication about science does not occur in a vacuum. At the individual level, its success depends on the beliefs that individuals bring to it, such that some scientific results are difficult to comprehend whereas others go without saying. In some cases, communication just needs to fill the gaps in laypeople's mental models. In other cases, it needs to overcome misconceptions, sometimes the product of clumsy communication, sometimes the result of effective disinformation campaigns. Learning what laypeople know and need to know requires empirical research.

At the social level, the success of scientists' communication depends on their awareness of the role that their work plays in the public discourse. Although scientists may know more than anyone about the facts and uncertainties, applications of that science can raise complex ethical, legal, and social questions, regarding which reasonable people may disagree. As a result, if scientists want to be effective in their communication, they must understand and address the perspectives of interest groups, policy makers, businesses, and other players in debates over decisions that require scientific expertise. Here, too, they need empirical research to inform their understanding of what others think about topics such as whether researchers in synthetic biology should try to create life, or what the ethical boundaries of stem cell research should be.

At both the individual (micro) level and the social (macro) level, the stakes are too high to rely on intuitive theories and anecdotal observations about communication. It would be foolish to ignore the best available scientific evidence. The social, behavioral, and decision sciences have documented the many ways in which intuitions about others and about the effectiveness of communication can go wrong-and how those biases grow with the distance between the parties. The unique ways of looking at the world that make scientists such indispensable sources of information may also distance them from nonscientists. Making the most of what science has to offer society requires the giveand-take of two-way communication with laypeople. Those interactions can be direct as in classrooms and social settings, or indirect, through the mediation of research helping scientists to understand the public and vice versa.

Ineffective communication can be costly to science as well as to society. Science requires the public's support. Whether it is forthcoming depends on how much the public trusts and values science. Is the research worth the investment? Does it produce the jobs and health that it promises? Do scientists put the public's welfare above their interests? Do they care whether their work is used or misused? Here, too, the sciences of communication can help scientists to learn and address the questions that their audiences are asking. That process may even redirect some of their research in new and interesting directions.

Effective science-public communication depends, in part, on foundations laid years earlier. The more that laypeople have absorbed in science classes and informal science education, the better chance they have of grasping the science relevant to the decisions that they face. The more effectively scientists have built bridges with the rest of society, the better chance they have of getting a hearing for their work. The stronger the networks among other stakeholders, the better chance they have to pose their questions to scientists and to resolve the societal implications of the answers.

Just as there is science to be communicated, there is a science of communication. Indeed, there are many sciences of communication. Psychologists know something about how to display information most clearly, how to convey uncertainty, and when emotions support (or cloud) understanding. Sociologists know something about how interpersonal networks form and dissolve, how information and trust travel within networks, and when crowds are wise or foolish. Decision scientists know something about how to characterize uncertainty, how to predict the performance of complex systems, and how to evaluate forecasts in the light of experience. Communication scientists know something about how messages flow through diverse communications channels, how stakeholders interpret them, and how those processes affect beliefs, attitudes, and behaviors about science and scientists.

Some of these communication scientists are found in disciplinary departments, such as psychology, sociology, and political science. Some are in interdisciplinary ones, such as geography, business, and public policy. Communication departments include scientists who view themselves in both ways. Wherever they reside, these scientists rarely get to converse at length, especially with respect to the communication of science, where all have something to say and to learn. The Arthur M. Sackler Colloquia are dedicated to creating the opportunities for such conversations and for future collaborations. This special issue of PNAS records some of those exchanges from the colloquium on "The Science of Science Communication," held at the National Academy of Sciences, May 21-22, 2012.

The papers here follow the flow of the colloquium. They begin with overviews of the

\footnotetext{
This paper results from the Arthur M. Sackler Colloquium of the National Academy of Sciences, "The Science of Science Communication," held May 21-22, 2012, at the National Academy of Sciences in Washington, DC. The complete program and audio files of most presentations are available on the NAS Web site at www. nasonline.org/science-communication.
}

Author contributions: B.F. and D.A.S. wrote the paper

The authors declare no conflict of interest.

${ }^{1}$ To whom correspondence should be addressed. E-mail: baruch@ cmu.edu. 
relevant behavioral and social science, giving first the "micro" perspective of communication at the individual level and then the "macro" perspective of the social context within which communication takes place. The papers follow this micro-to-macro arc, beginning with the analytical research needed to reduce the vast volume of research that scientists could communicate to the kernels of information that their audiences most need to know. The articles include overviews of cognitive and psychological processes at the individual level, of the impacts of rapidly changing offline and online media infrastructures, and of scientists' beliefs and attitudes regarding their role in communicating science to nonexpert audiences.

Throughout the special issue, communication is viewed as a two-way process, in which scientists must listen as well as speak, if they are to identify the most relevant information and assess their success at conveying it. Throughout the issue, the communication of science is held to the same evidentiary standards as the science being communicated. It should be informed by existing science (e.g., studies of how to avoid confusion between correlation and causality), rather than just intuition. It should subject itself to empirical evaluation, recognizing that even the best behavioral and social science cannot confidently predict human behavior in complex, novel settings.

Given its mission, the colloquium also brought communication scientists together with those who need their work, including scientists who could contribute to public discourse and decision makers and communication practitioners who could use that knowledge. An early session set the stage by addressing the communication challenges faced by four applied sciences emerging roughly a decade apart and reflecting the social context of their day: nuclear power, agricultural biotechnology, nanotechnology, and geoengineering. Another session was honored by four presidential science advisors, discussing their communication challenges and opportunities. A concluding session featured scientists engaged in the communication process, including a representative from the National Academy of Sciences' own Science and Entertainment Exchange, stimulating and harnessing the entertainment industry's desire to get the science right.

The colloquium filled the Academy auditorium and was streamed to 3,500 locations. Its success prompted a second Sackler Colloquium on "The Science of Science Communication," September 23-25, 2013. 